\title{
Predictors of Discordant Reports of Sexual and HIV/Sexually Transmitted Infection Risk Behaviors Among Heterosexual Couples
}

\author{
SUSAN S. WITTE, PHD, NABILA EL-BASSEL, DSW, LOUISA GILBERT, MSSW, ELWIN WU, PHD, \\ AND MINGWAY CHANG, MA
}

\begin{abstract}
Objectives: Assessments undertaken as part of couple-based HIV/ sexually transmitted infection (STI) prevention intervention studies offer opportunities to expand our understanding of couple reporting of sexual and HIV/STI risk behavior. Increases in heterosexual transmission of HIV worldwide support more attention on the quality and use of couple-level sexual risk assessment.

Study Design: This study examined interpartner concordance of self-reported sexual behaviors and HIV/STI risk behaviors among 217 women and their main male sexual partners at high risk for HIV/STI transmission and further explored specific individual and relationship characteristics by partner gender associated with discordant reporting of sexual and HIV/STI risk behaviors.

Results: Consistent with prior studies, findings suggest fair to substantial agreement between partners on reports of most sexual and HIV/STI risk behavior, but only poor to fair agreement on reports of concurrent sexual behaviors and drug or alcohol use. Factors significantly associated with discordant reporting of sexual behaviors included length of couple relationship, level of relationship satisfaction, female partner's marital status, and male partner's HIV status, ethnicity, and age.

Conclusions: Individual- and relationship-level factors predicting discordant partner reports of sexual and sexual risk behaviors highlight an opportunity to improve couple assessment by anticipating such discrepancies and developing effective mechanisms of quality assurance to avoid, address, or better explain such discordance in couple data sets.
\end{abstract}

HETEROSEXUAL TRANSMISSION OF HIV IS the dominant route of infection worldwide, indicating a critical need for reliable assessments of HIV sexual risk behaviors and analyses of the quality and use of couple-level data assessment. Retrospective self-reporting remains the primary mode of assessing sexual and $\mathrm{HIV} / \mathrm{sexually}$ transmitted infection (STI) risk behaviors. A number of studies have documented interpartner concordance among heterosexual couples, ${ }^{1-4}$ although some researchers have raised concerns about the reliability and validity of such assessments. ${ }^{5-9}$

Several studies summarize the factors associated with lack of concordance in partner reports. For example, Weinhardt et $\mathrm{al}^{8}$ summarize what is known about measurement error and participation bias in extant literature on sexual self-reports in general, and how these

This study was supported by NIMH grant MH57145 to Dr. El-Bassel. Correspondence: Susan S. Witte, PhD, Social Intervention Group, Columbia University School of Social Work, 1255 Amsterdam Avenue, \#813, New York, NY 10027. E-mail: ssw12@ columbia.edu.

Received for publication May 15, 2006, and accepted July 19, 2006.
From the Social Intervention Group, Columbia University School of Social Work, New York, NY

may contribute to discordant reports between partners. Methodological and participant influences examined include respondent influences, instrument variables, mode effects, interviewer variables, and participation bias. It has been suggested that self-presentation bias may be related to issues of individual demographic or relationship characteristics such as levels of sexual comfort and willingness to disclose sexual information, as well as potential ethnic differences, and may help explain discordance between partners. ${ }^{7}$

A few studies quantitatively explored individual participant characteristics associated with concordance of partner reporting of sexual behaviors. ${ }^{1,10,11}$ Nevertheless, there are considerable gaps in the literature on why concordance of responses on HIV sexual behavior among heterosexual couples occurs or what specific individual or relationship variables might predict discordant reporting. No study has systematically explored both individuallevel and relationship-level predictors of discordance in direct partner self-reports.

The purpose of this study was to explore the concordance of reported sexual behaviors and sexual risk behaviors among 217 women and their main male sexual partners at high risk for sexually transmitted HIV infection and to identify individual and relationship factors that might predict discordant reports of sexual and sexual risk behaviors between partners. The research questions addressed by the study are:

1. What is the concordance of reports of sexual behavior (oral, anal, vaginal sexual intercourse) and sexual risk behavior (male and female condom use during sexual intercourse, sexual intercourse under the influence of alcohol or drugs) among 217 heterosexual women and their main sexual partners?

2. What individual-level characteristics (age, ethnicity, marital status, level of education, HIV status) and relationship-level characteristics (length of relationship, sexual comfort, relationship satisfaction, confidence in the relationship) predict discordant reporting among 217 heterosexual women and their sexual partners?

This study provides additional data on sexual and sexual risk behaviors among couples at high risk for HIV/STI sexual transmission. In addition, a range of individual and relationship factors 
are explored to determine if they may predict discordant reports of sexual and HIV/STI risk behaviors between partners. Identifying factors predicting discordant partner reports may improve couple assessment by anticipating discrepancies and help develop effective mechanisms of quality assurance to avoid, address, or better explain discordance in couple data sets.

\section{Methods}

Data for this study come from a randomized clinical trial testing the efficacy of a relationship-based HIV/STI prevention intervention to reduce sexual risk behaviors among heterosexual couples at risk for sexual HIV/STI transmission. ${ }^{12-14}$ Female patients from an urban, outpatient clinic were recruited and screened for participation; eligible women recruited their main partners to participate. A woman was eligible for the study if she reported practicing unprotected vaginal or anal intercourse within the prior 90 days with a partner whom she believed was putting her at risk of HIV infection in one of several ways: he was HIV-positive, currently injecting drugs, had been diagnosed with a sexually transmitted disease (STD) or experienced STD symptoms within the prior 90 days, or had had sex with extradyadic partners within the prior 90 days. Partnerships in which severe sexual or physical abuse was reported by the woman (characterized as "severe" on the physical aggression and sexual coercion scales of the Revised Conflict Tactics Scale) $)^{15}$ were excluded (see El-Bassel et al ${ }^{13}$ and Witte et al ${ }^{16}$ for complete discussion of study design, recruitment, and enrollment strategies for Project Connect). The final sample for this study was 217 couples.

After obtaining informed consent, eligible women and their partners completed a baseline interview: male staff interviewed the male partner and female staff interviewed the female partner in a private, separate office. Interviews were approximately 90 minutes in duration and participants were compensated $\$ 30$ for their time. After completion of the baseline interview, couples were randomized to one of 3 study conditions. Follow-up interviews were completed with both the women and the men at 3 months and with the woman only at 12 months. Data reported are from the baseline assessments of all participants.

\section{Measures}

Demographic Characteristics. Background demographic variables measured included age, race/ethnicity, marital status, income, education, and HIV status.

Sexual Risk Behavior. Sexual risk behaviors were measured using the Sexual Risk Behavior Questionnaire (SRBQ). The SRBQ assesses sexual behaviors 90 days before the interview by eliciting self-reported sexual behavior with the study partner. Shared sexual behaviors were measured dichotomously and included whether, within the prior 90 days, participants engaged in vaginal sex, anal sex, female to male oral sex (fellatio), or male to female oral sex (cunnilingus) with their partner. To assess sexual risk behaviors, participants were asked if they had used a male condom with their partner during vaginal, anal, or oral sex in the 90 days before assessment; used a female condom with their partner during vaginal, anal, or oral sex; used drugs before or during sex with their partner; if their partner had used drugs before or during sex; if they had used alcohol before or during sex with their partner; and if their partner had used alcohol before or during sex in the prior 90 days. The measure demonstrates good internal reliability $(\alpha=.80)$.

Relationship Characteristics. Relationship characteristics included length of relationship, sexual comfort, relationship satis- faction, and confidence in the relationship. We dichotomized relationship characteristics for analysis, identifying the median values for each variable among all respondents. Length of relationship was measured from the date of first sexual intercourse to the date of baseline assessment. We dichotomized the variable, defining "longer-term" relationships as having lasted 6 years or more. Sexual comfort was measured using a 10-item scale regarding comfort with sexual issues and one's own sexuality. ${ }^{17} \mathrm{Re}$ sponses ranged on a 5-point scale from "very uncomfortable" to "very comfortable." Total scores ranged from 10 to 50 with higher scores representing greater sexual comfort. The measure demonstrated good internal reliability $(\alpha=.79)$. Based on the median value for total scores among participants, "high" sexual comfort was defined as 46 or above. Relationship satisfaction was measured using the Relationship Assessment Scale (RAS), ${ }^{18,19}$ a 7-item measure of global relationship satisfaction. Responses are on a 5-point scale with total scores ranging from 7 to 35 with higher scores indicating greater relationship satisfaction. The RAS is highly correlated with the Dyadic Adjustment Scale ${ }^{20}$ and demonstrates good test-retest reliability and consistent measurement properties across samples of ethnically and age-diverse couples $(\alpha=.82)$. Based on median values among participants, "high" satisfaction was defined by scores of 30 and above. Relationship confidence was measured by asking participants how confident they were that they would remain in the relationship for the next 12 months. Originally measured categorically on a 5-point scale from (1) "not at all confident" to (5) "very confident," confidence in the relationship was dichotomized by combining "very confident" and "confident" (scores of 4 or 5) as "confident" and "not at all confident," "not confident," and "a little confident" (scores of 1, 2, or 3) as "not confident."

\section{Data Analysis}

Frequency distributions are used to illustrate sample characteristics about age, ethnicity, marital status, income, education, and HIV status. The kappa ( $\kappa$ ) statistic was used to determine concordance of sexual and drug risk behaviors beyond what would be expected by chance between partners for categorical and ordinal data. We report values of $\kappa$ as zero to 0.20 indicating poor agreement, 0.21 to 0.40 indicating fair agreement, 0.41 to 0.60 indicating moderate agreement, 0.61 to 0.80 indicating substantial agreement, and $>.81$ and above indicating excellent agreement. ${ }^{21,22}$ Percentage agreement (defined as the number of matching responses between partners for a single measure divided by the number of couples) was used to support interpretation of $\kappa$ statistics and to highlight areas of discordance in partner reports. Kappa values may be very low when behaviors are reported at a very high or very low frequency by both couple members, even if a relatively small proportion of reports are actually inconsistent, ${ }^{23}$ which can result in overly conservative reliability.

Pearson's correlations, $t$ tests, and Spearman's correlations were used to assess agreement of continuous variables taking into account that correlations indicate proportional rather than exact agreement. We used results from Wilcoxon's signed rank test to assess the significance of differences between median values derived from continuous variables determining whether discordant responses fall equally in one direction or if one partner group (e.g., men) tends to report more often in a particular direction. Finally, we used logistic regression to identify which individual and relationship characteristics predicted discordant reports on shared sexual behaviors among couples. The choice of logistic regression over OLS was driven by the binary dependent variable of concordance versus discordance. Predictors included both men's and 
women's characteristics. Odds ratios and their associated 95\% confidence intervals are reported.

\section{Results}

\section{Demographic Characteristics}

Male and female demographic characteristics are similar (see Table 1). Most were between 26 and 45 years of age, of black or Latino/a race/ethnicity, were never married, had incomes of less than $\$ 5,000$ annually, had not completed high school, and were HIV-negative.

\section{Concordance of Sexual Behaviors}

Table 2 illustrates concordance of sexual behaviors among couples. Percentage agreement for dichotomously measured sexual behaviors and condom use was high, ranging from $74 \%$ (cunnilingus) to $100 \%$ (vaginal sex). The majority of partners reported consistently whether they had engaged in anal or oral sex (cunnilingus or fellatio) in the prior 90 days. Forty-one couples (19\%) gave discordant responses regarding anal sex, 52 couples (24\%) gave discordant responses regarding fellatio, and 57 couples (26\%) gave discordant responses regarding cunnilingus. Corresponding $\kappa$ statistics for sexual behavior reports suggested a range from fair

\section{TABLE 1. Demographic Characteristics}

\begin{tabular}{|c|c|c|}
\hline Variable & Women (\%) & Men (\%) \\
\hline \multicolumn{3}{|l|}{ Age $(\mathrm{N}:$ women $=217$, men $=217)$} \\
\hline Below 25 y old & $22(10.1)$ & $18(8.3)$ \\
\hline $26-35$ y old & 78 (35.9) & $64(29.5)$ \\
\hline Above 36 y old & $117(53.9)$ & $135(62.2)$ \\
\hline \multicolumn{3}{|l|}{ Ethnicity $(\mathrm{N}$ : women $=217$, men $=217)$} \\
\hline Black & $118(54.4)$ & $119(54.8)$ \\
\hline Hispanic & 86 (39.6) & $82(37.8)$ \\
\hline $\begin{array}{l}\text { White, Asian, Pacific Islander, } \\
\text { and others }\end{array}$ & $13(6.0)$ & $16(7.4)$ \\
\hline \multicolumn{3}{|l|}{$\begin{array}{l}\text { Marital status }(\mathrm{N} \text { : women }=217 \\
\quad \text { men }=217)\end{array}$} \\
\hline Single, never married & $130(59.9)$ & $120(55.3)$ \\
\hline Divorced, separated, widowed & 54 (24.9) & $66(30.4)$ \\
\hline Married & $33(15.2)$ & $31(14.3)$ \\
\hline \multicolumn{3}{|l|}{ Income $(\mathrm{N}$ : women $=217$, men $=216)$} \\
\hline Less than $\$ 5,000$ & $148(68.2)$ & $109(50.5)$ \\
\hline$\$ 5,000-\$ 9,999$ & $42(19.4)$ & $49(22.7)$ \\
\hline More than $\$ 10,000$ & 27 (12.4) & $58(26.9)$ \\
\hline \multicolumn{3}{|l|}{$\begin{array}{l}\text { Education }(\mathrm{N} \text { : women }=217 \\
\quad \text { men }=217 \text { ) }\end{array}$} \\
\hline Less than high school & $144(66.4)$ & $142(65.4)$ \\
\hline High school & $73(33.6)$ & $75(34.6)$ \\
\hline \multicolumn{3}{|l|}{$\begin{array}{l}\text { HIV status }(\mathrm{N}: \text { women }=217 \\
\text { men }=217)\end{array}$} \\
\hline Negative & $152(70.5)$ & $147(67.7)$ \\
\hline Positive & 47 (21.7) & $43(19.8)$ \\
\hline Unknown & $18(8.3)$ & $27(12.4)$ \\
\hline $\begin{array}{l}\text { Low sexual comfort }(\mathrm{N} \text { : women }=217 \\
\quad \text { men }=216)^{\star}\end{array}$ & $129(59.5)$ & $86(39.8)$ \\
\hline $\begin{array}{l}\text { Low relationship satisfaction } \\
\quad(\mathrm{N}: \text { women }=217, \text { men }=217)^{\dagger}\end{array}$ & $122(56.2)$ & $105(48.4)$ \\
\hline $\begin{array}{l}\text { Confidence in relationship ( } \mathrm{N} \text { : women = } \\
216 \text {, men }=216 \text { ) }\end{array}$ & $200(92.6)$ & $193(89.4)$ \\
\hline $\begin{array}{l}\text { Long relationship }(\mathrm{N} \text { : women }=217, \\
\qquad \text { men }=216)^{\ddagger}\end{array}$ & $55(25.4)$ & $57(26.4)$ \\
\hline
\end{tabular}

${ }^{*}$ Cutoffs for sexual comfort scale: low (10-45), high (46-50).

${ }^{\dagger}$ Cutoffs for relationship satisfaction scale: low (7-29), high (30-35).

${ }^{\ddagger}$ Cutoffs for length of relationship: short $(<6)$, long $(\geq 6)$.
TABLE 2. Concordance of Couple's Reported Sexual Behaviors

\begin{tabular}{|c|c|c|}
\hline Concordant Category & Agreement (\%) & Kappa \\
\hline $\begin{array}{l}\text { Had vaginal sex in the past } 90 \mathrm{~d} \\
\qquad(\mathrm{~N}=217)\end{array}$ & & - \\
\hline Both report yes & $217(100.0)$ & \\
\hline Both report no & $0(0.0)$ & \\
\hline Discordant & $0(0.0)$ & \\
\hline $\begin{array}{l}\text { Had anal sex in the past } 90 \mathrm{~d} \\
\qquad(\mathrm{~N}=217)\end{array}$ & & 0.34 \\
\hline Both report yes & $17(7.8)$ & \\
\hline Both report no & 159 (73.3) & \\
\hline Discordant & $41(18.9)$ & \\
\hline $\begin{array}{l}\text { Had oral sex (female to male) in } \\
\text { the past } 90 \mathrm{~d}(\mathrm{~N}=217)\end{array}$ & & 0.46 \\
\hline Both report yes & $121(55.8)$ & \\
\hline Both report no & $44(20.3)$ & \\
\hline Discordant & $52(24.0)$ & \\
\hline $\begin{array}{l}\text { Had oral sex (male to female) in } \\
\text { the past } 90 \mathrm{~d}(\mathrm{~N}=217)\end{array}$ & & 0.40 \\
\hline Both report yes & $119(54.8)$ & \\
\hline Both report no & 41 (18.9) & \\
\hline Discordant & $57(26.3)$ & \\
\hline
\end{tabular}

agreement $(0.34)$ for anal sex to moderate agreement $(0.46)$ for fellatio.

Concordance of HIV/Sexually Transmitted Infection Sexual Risk Behaviors

Percentage agreement for HIV/STI risk behaviors, including condom use, was high, ranging from $85 \%$ agreement regarding whether the couple used a male condom during intercourse in the prior 90 days to $95 \%$ agreement regarding whether the couple used a female condom during intercourse in the prior 90 days (see Table 3 ). Thirty-three couples (15\%) reported discrepancies in male condom use in the prior 90 days; 11 couples (5\%) reported a discrepancy in female condom use. Kappa values suggested substantial concordance for male and any condom use (0.63 and 0.63 , respectively), but only fair concordance $(0.40)$ for female condom use. Because the female condom percentage agreement is so high, the kappa statistic may be experiencing sensitivity limitations. Percentage agreement for reports of sexual intercourse while under the influence of alcohol or drug use among partners in the prior 90 days ranged from $66 \%$ for female partner drug use to $68 \%$ for male partner alcohol use. On all 4 of these measures, approximately one third of couples had discordant reports regarding whether their partner was under the influence of drugs or alcohol during sexual intercourse in the prior 90 days. Kappa values suggest poor to fair concordance on all of these variables (range, 0.2-0.33).

Table 4 describes the percentage agreement of couple reports of the same sexual behaviors, but measured continuously, in the prior 90 days (frequency of vaginal, anal, and oral intercourse). These data agree with the dichotomous data presented in Table 2. Means for male and female partner reports are not significantly different, and Pearson's and Spearman's correlation coefficients are all found to be significant. Wilcoxon signed ranks tests suggest that in all but one category there is no significant difference in the direction of the reports by gender; higher or lower frequencies of behaviors were equally reported by both genders. However, the significant finding related to the frequency of fellatio indicates that male partners tend to consistently report higher frequencies of this behavior than do their female partners. 
TABLE 3. Concordance of Couple's Reported HIV/Sexually Transmitted Infection Risk Behaviors in the Past $90 \mathrm{D}$

\begin{tabular}{|c|c|c|}
\hline Concordant Category & Agreement (\%) & Kappa \\
\hline Used male condom $(\mathrm{N}=217)$ & & 0.63 \\
\hline Both report yes & $45(20.7)$ & \\
\hline Both report no & 139 (64.1) & \\
\hline Discordant & 33 (15.2) & \\
\hline Used female condom $(\mathrm{N}=217)$ & & 0.40 \\
\hline Both report yes & $4(1.8)$ & \\
\hline Both report no & $202(93.1)$ & \\
\hline Discordant & $11(5.1)$ & \\
\hline Used any condom $(\mathrm{N}=217)$ & & 0.63 \\
\hline Both report yes & $46(21.2)$ & \\
\hline Both report no & 138 (63.6) & \\
\hline Discordant & 33 (15.3) & \\
\hline $\begin{array}{l}\text { Female partner drug use during sex } \\
\qquad(\mathrm{N}=214)\end{array}$ & & 0.27 \\
\hline Both report ever & $41(19.2)$ & \\
\hline Both report never & $100(46.7)$ & \\
\hline Discordant & $73(34.1)$ & \\
\hline $\begin{array}{l}\text { Male partner drug use during sex } \\
\qquad(N=211)\end{array}$ & & 0.33 \\
\hline Both report ever & $60(28.4)$ & \\
\hline Both report never & $80(37.9)$ & \\
\hline Discordant & 71 (33.7) & \\
\hline $\begin{array}{l}\text { Female partner alcohol use during sex } \\
\qquad(N=215)\end{array}$ & & 0.20 \\
\hline Both report ever & $29(13.5)$ & \\
\hline Both report never & $113(52.6)$ & \\
\hline Discordant & 73 (33.9) & \\
\hline $\begin{array}{l}\text { Male partner alcohol use during sex } \\
\qquad(\mathrm{N}=213)\end{array}$ & & 0.30 \\
\hline Both report ever & $41(19.2)$ & \\
\hline Both report never & $104(48.8)$ & \\
\hline Discordant & 68 (31.9) & \\
\hline
\end{tabular}

\section{Individual- and Relationship-Level Predictors of Discordant Couple Reports}

Selected individual demographic and relationship-level characteristics appeared to successfully predict discordance among couples on their shared sexual behaviors (see Table 5). Although we conducted analyses for all sexual and HIV/STI risk and concurrent drug/alcohol use behaviors (see Tables 2 and 3), 5 of these shared sexual behaviors yielded significant findings (see Table 5). The direction of discordance for significant findings is provided in Table 5 and is addressed in the "Discussion" section.
Couples in which the female partner reported low relationship satisfaction were significantly more likely to have discordant reports on fellatio compared with those in which the female partner reported high relationship satisfaction. Couples in which the male partner was Latino (compared with black, odds ratio $[\mathrm{OR}]=3.4$ ) or was HIV-positive (compared with HIV-negative, OR $=5.9$ ) were more likely to have discordant reports on fellatio.

Couples in which the female partner's marital status was divorced, separated, or widowed (compared with single, $\mathrm{OR}=3.3$ ) or in which the male partner was Latino (compared with black, $\mathrm{OR}=6.9$ ) were more likely to have discordant reports on cunnilingus. Couples with relationships of 6 years or greater duration (compared with less than 6 years, $\mathrm{OR}=2.6$ ) were more likely to have discordant reports on cunnilingus.

Couples in which the female partner was married (compared with single, $\mathrm{OR}=.3$ ) were less likely to have discordant reports on female partners' use of drugs during sex. Couples in which the female partner had low relationship satisfaction (compared with high, $\mathrm{OR}=2.3$ ) and those in relationships of 6 years in duration or more (compared with less than 6 years, OR $=2.4$ ) were more likely to have discordant reports on female partner's use of drugs. Couples in which the male partner had low relationship satisfaction (compared with high, $\mathrm{OR}=.3$ ) were less likely to have discordant reports on female partners' use of drugs during sex.

Couples in which the male partner reported low relationship satisfaction compared with high, $\mathrm{OR}=.5$ ) were less likely to have discordant reports on the male partner's use of drugs during sex; couples in longer relationships (compared with couples in less than 6 years relationship, $\mathrm{OR}=2.3$ ) were more likely to have discordant reports of the same.

Finally, couples in which the female partner was married (compared with single, $\mathrm{OR}=.2$ ) were less likely to have discordant reports on whether the male partner used alcohol during sex. Couples in which the female partner reported low relationship satisfaction (compared with high, $\mathrm{OR}=2.0$ ) and in which the male partner was aged 26 to 35 (compared with 36 or older, OR = 2.4) were more likely to have discordant reports on male partner's use of alcohol during sex.

Not shown in the tables are the condom use variables in which there were 2 significant findings: couples in which male partners were HIV-positive were more likely to have discordant reports on whether the couple used male condoms $(\mathrm{OR}=9.4)$ and whether they used any (male and/or female) condoms $(\mathrm{OR}=8.5) \mathrm{com}$ pared with those in which the men were HIV-negative.

TABLE 4. Concordance of Continuous Sexual Behavior Variables: t Test, Pearson's Correlation ( $r)$, Spearman's Correlation $(\rho)$, and Wilcoxon Signed Rank Test $(z)(N=217)$

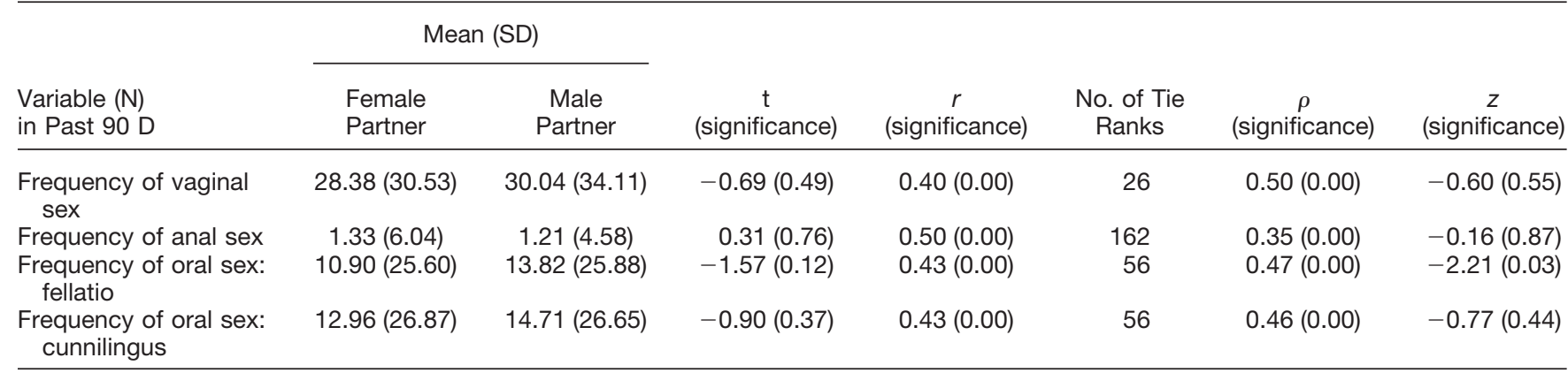

Note: Significance based on 2-tailed.

SD indicates standard deviation. 
TABLE 5. Logistic Regressions of Discordance Between Couple's Reports of Sexual Behaviors: Odds Ratios and 95\% Confidence Intervals

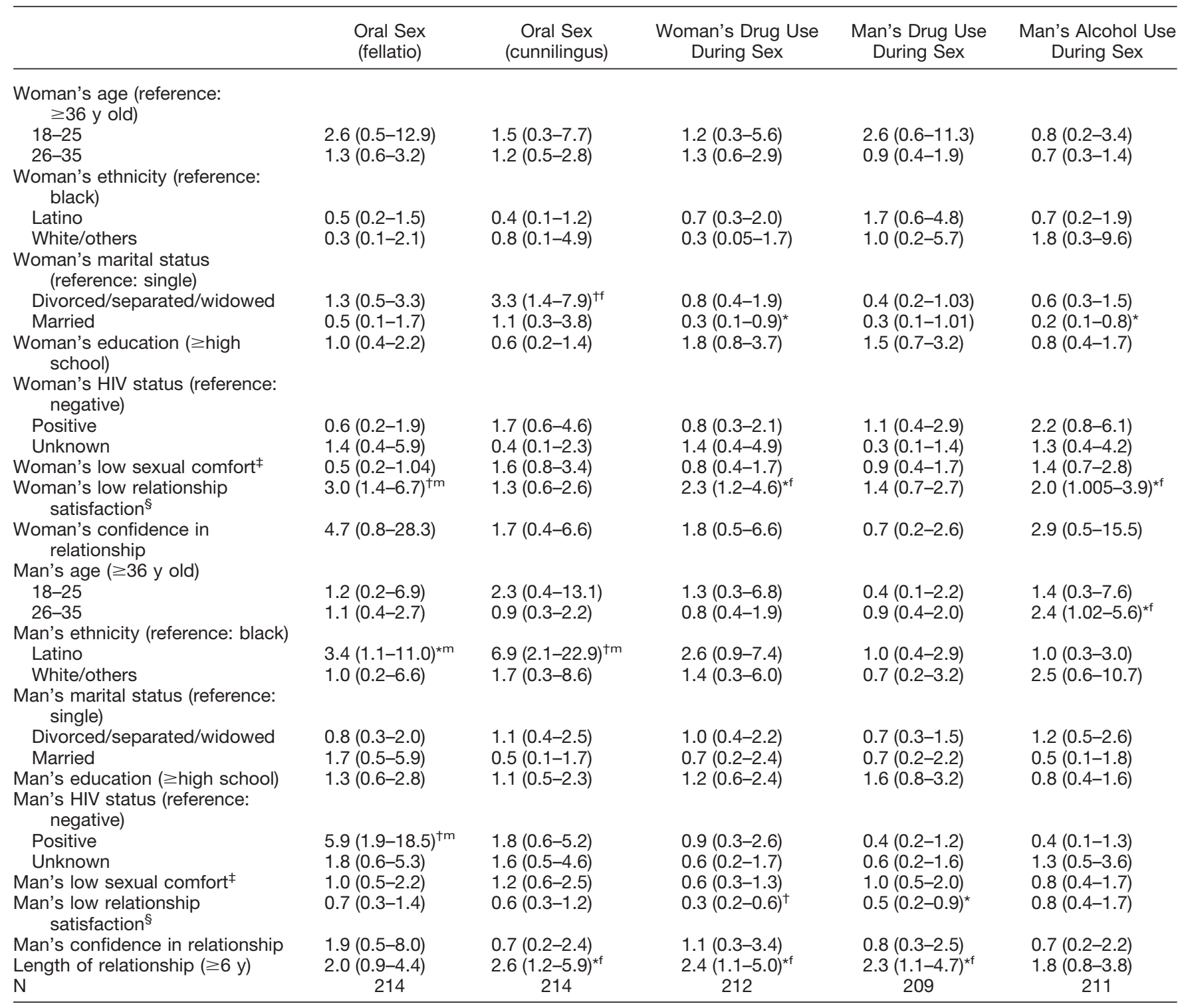

${ }^{\star} P<0.05$.

${ }^{\dagger} P<0.01$.

${ }^{\ddagger}$ Cutoffs for sexual comfort scale: low (10-45), high (46-50).

§Cutoffs for relationship satisfaction scale: low (7-29), high (30-35).

$\mathrm{m}=$ male partner reported "yes" more often than female partner; $f=$ female partner reported "yes" more often than male partner.

\section{Discussion}

Consistent with prior studies, interpartner concordance comparison of self-reported sexual and sexual risk behaviors in the prior 90 days yielded fair to substantial agreement on the $\kappa$ index. Of concern is the poor to fair agreement in reports of sexual behavior under the influence of alcohol and drugs. Looking at both the predictors and the direction of discordance suggests that among couples with greater likelihood of discordant reporting, female partners more often endorse both their male partners' and their own drug or alcohol use during sex. In couples in which the female partner's relationship satisfaction is low, relationship duration is at least 6 years, and her male partner's age is 26 to 35 years, female partners report men's alcohol and drug use during sex more often than do their partners. Underreporting drug and alcohol use during sex by male partners may be an issue of recall, social desirability, or denial. In these same couples (low female partner relationship satisfaction and longer relationship duration), female partners endorse more often their own drug use during sex compared with their partners. These findings suggest that in these relationships, male partners are underreporting their partners' use of drugs during sex, which could either be related to a lack of awareness or a lack of willingness to report knowledge of such behaviorsperhaps as a result of self-presentation bias or other issues, including social desirability. Their own impairment through use of drugs 
or alcohol may contribute to their lack of awareness of female partner's alcohol or drug use during sex. Use of alcohol or drugs may be consistent with relationships in which one or both partners is less comfortable or satisfied with the relationship, for example, as a "lubricant" for engaging in sexual behavior, or when one or the other partner has difficulty or less comfort engaging in sex. This finding emphasizes the importance of routine assessment of concurrent alcohol or drug use during sexual risk or sexual behaviors that could lead to risk.

Findings suggest also that among couples in which the male partner is HIV-positive, there is significant likelihood of discordant reporting on condom use. This is of particular concern, because the direction of endorsement of condom use is higher among male partners and lower among female partners. Because this is a measure of whether condoms were used at all in the prior 90 days, one interpretation of this finding is that overreporting by male partners seems more consistent with social desirability and self-presentation bias than would underreporting by female partners. This finding may underscore the fact that power differentials in heterosexual relationships make the barrier method protection difficult for women to negotiate. Interventions may support increased communication and negotiation skills among couples, thereby reducing sexual risk behaviors and subsequent HIV/STI transmission.

The finding that among couples with a Latino male partnerthat there was a greater likelihood of discordant reporting on oral sex-may be consistent with ethnic or cultural considerations among some Latino communities, in which female partners may be traditionally or culturally more sexually conservative and therefore less willing to reveal sexual activity to an interviewer or to machismo values leading to higher reporting among men. Furthermore, the characteristic of simpatia (the desire to please others and to be likable) in Latino culture may have influenced social desirability bias on the part of one or the other partner. ${ }^{7}$

Contrary to findings by Upchurch et al, we found that agreement in sexual reports of some behaviors differed by marital status, but only for women. Divorced, separated, or widowed women were more likely to report differently on engagement in cunnilingus, whereas married women were less likely to report differently than their partners on whether she used drugs during sex or he used alcohol. As stated previously, among these examples of discordance, female partners endorsed their own and their partners' drug and alcohol use more often than did their partners.

Although Seal ${ }^{11}$ found that a younger male partner correlated with more agreement among sexual reports, our findings only found this to be true among couples in which the male partner was 26 to 35 years old when there was more likely to be discordant reports on his alcohol use during sex (with the female partner reporting it more often than the male partner). Age may play a role in levels of maturity, concerns about social desirability, length of relationship, and issues of self-presentation. Underreporting by men of their alcohol use during sex may be the result of social desirability or denial. Because this was specifically related to alcohol use, it is also possible that female partners overreport as a result of lingering physical signs, including alcohol on one's breath consistent with earlier alcohol use but not immediately before or during sex.

The only characteristic found to predict discordant reporting among both men and women was level of relationship satisfaction. However, in couples in which relationship satisfaction was low among women, there was a greater likelihood for discordance, whereas when the relationship satisfaction was low among men, there was less likelihood for discordance. Future studies with couples should incorporate assessments for relationship satisfac- tion to understand better the relationship between this important couple construct and reports of sexual risk outcomes.

\section{Study Limitations}

Although we may identify selected demographic and relationship factors as respondent factors, and therefore potentially related to self-presentation, they may also be related to issues of study design or interviewer factors. Our study design does not allow us to isolate these influences. The use of face-to-face interviews may have resulted in differential measurement error in reports of more or less risk behavior based on respondent, interviewer, or instrument factors. ${ }^{7,24}$ As noted by Catania et al, ${ }^{7}$ both data and the study may be influenced by participant bias. We recruited women first, who then enrolled their male partners, which likely led to male participants more willing to or interested in participating in a research study. We also excluded couples in relationships in which there was severe relationship violence. Also, all assessment questions were based on 90-day reports of behaviors for which recall may be challenging. More studies that compare data for recall periods of differing length might help determine if consistency in predictors of discordant reports differs by shorter or longer recall periods. Next, findings are generalizable only to urban couples at high risk of sexual HIV/STI transmission as defined by the eligibility criteria. Finally, this is a new study exploring an area of behavioral research that requires more work. Our exploration was not theoretically embedded or derived. Our findings are only the beginning, indicating the need for more systematic exploration of the possible reasons for discordant reporting.

\section{Implications for Future Research}

Catania et $\mathrm{al}^{7}$ made the first compelling argument for the importance of respondent factors and self-presentation bias in AIDSrelated behavioral research about self-reports of specific sexual activities across sex, age, orientation, and cultural subgroups at risk for HIV/STIs. However, there has been little systematic research on the influence of respondent factors on reports among couples since that research, despite increased rates of heterosexual transmission worldwide. Findings suggest that there might be identifiable factors that could assist in determining which couples would be more likely to make discordant reports, thereby guiding assessment and design features of future studies with targeted populations.

With the increased focus on couple-based interventions, there are opportunities to deepen our understanding of couple reporting on sexual and HIV/STI risk behavior. Partner data are rich but complex. How can we best explore it and make use of what it tells us? To gain a better understanding of individual- and couple-level issues/concerns related to sexual self-report, we need more direct, qualitative inquiries to be conducted in which couples are systematically debriefed based on their differing reports of sexual behaviors. Such a study would pose challenges to ethical conduct and relationship safety but should nevertheless be pursued. Future quantitative work should continue to look at rates of concordance and simultaneously attempt to isolate factors influencing rates of discordance among reporting. Moreover, we need to develop better quality assurance on dyadic reports and/or more systematic inquiry of couples regarding why a partner believes his or her report may differ from his or her partners' report: strong designs that can capture data through multiple assessment venues or modes, with differing interviewer characteristics, over brief and longer recall periods, and incorporating assessments for social desirability and specific self-presentation biases. 


\section{References}

1. Ochs EP, Binik YM. The use of couple data to determine the reliability of self-reported sexual behavior. Journal of Sex Research 1999; 36:374-384.

2. Van Duynhoven Y, Nagelkerke N, Van De Laar M. Reliability of self-reported sexual histories: Test-retest and interpartner comparison in a sexually transmitted diseases clinic. Sex Transm Dis 1999; 26:33-42.

3. Harvey SM, Thorburn Bird S, Henderson JT, Beckman LJ, Huszti HC. He said, she said: Concordance between sexual partners. Sex Transm Dis 2004; 31:185-191.

4. Sison JD, Gillespie B, Foxman B. Consistency of self-reported sexual behavior and condom use among current sex partners. Sex Transm Dis $2004 ; 31: 278-282$.

5. Lewontin RC. Sex, lies and social science. New York Review of Books 1995; 42:24-29.

6. Brody S. Patients misrepresenting their risk factors for AIDS. Int $\mathbf{J}$ STD AIDS 1995; 6:392-398.

7. Catania JA, Gibson DR, Chitwood DD, Coates TJ. Methodological problems in AIDS behavioral research: Influences on measurement error and participation bias in studies of sexual behavior. Psychol Bull 1990; 108:339-362.

8. Weinhardt LS, Forsyth AD, Carey MP, Jaworski BA, Durant LE. Reliability and validity of self report measures of HIV-related sexual behavior: Progress since 1990 and recommendations for research and practice. Arch Sex Behav 1998; 27:155-180.

9. Padian N, Aral S, Vranizan K, Bolan G. Reliability of sexual histories in heterosexual couples. Sex Transm Dis 1995; 22:169-172.

10. Upchurch MM, Weisman CS, Shepherd M, et al. Interpartner reliability of reporting of recent sexual behaviors. Am J Epidemiol 1991; 134:1159-1166.

11. Seal DW. Interpartner concordance of self-reported sexual behavior among college dating couples. Journal of Sex Research 1997; 34: $39-55$.
12. El-Bassel N, Witte S, Gilbert L, et al. HIV prevention for intimate couples: A relationship-based model. Families, Systems, and Health 2001; 19:379-395.

13. El-Bassel N, Witte SS, Gilbert L, et al. The efficacy of a relationshipbased HIV/STD prevention program for heterosexual couples. Am J Public Health 2003; 93:963-969.

14. El-Bassel N, Witte SS, Gilbert L, et al. Long term effects of an HIV/STI sexual risk reduction intervention for heterosexual couples. AIDS and Behavior 2005; 9:1-13.

15. Straus M, Hamby S, Boney-McCoy S, Sugarman D. The Revised Conflict Tactics Scales (CTS2): Development \& preliminary psychometric data. Journal of Family Issues 1996; 17:283-316.

16. Witte SS, El-Bassel N, Gilbert L, Wu E, Steinglass P. Recruitment of minority women and their main, male sexual partners in an HIV/STI prevention trial. Journal of Women's Health 2004; 13:1137-1147.

17. Marin BV, Gomez CA, Tschann J, Gregorich SE. Condom use in unmarried Latino men: A test of cultural constructs. Health Psychol $1997 ; 16: 458-467$

18. Hendrick SS. A generic measure of relationship satisfaction. Journal of Marriage and the Family 1988; 50:93-98.

19. Hendrick SS, Dicke A, Hendrick C. The relationship assessment scale. Journal of Social \& Personal Relationships 1998; 15:137-142.

20. Spanier GB. Measuring dyadic adjustment: New scales for assessing the quality of marriage and similar dyads. Journal of Marriage and the Family 1976; 38:15-28.

21. Fleiss JL. Statistical Methods for Rates and Proportions, 2nd ed. New York: Wiley, 1981.

22. Landis JR, Koch GG. The measurement of observer agreement for categorical data. Biometrics 1977; 33:159-174.

23. Cichetti DV, Feinstein AR. High agreement but low kappa: II. Resolving the paradoxes. J Clin Epidemiol 1990; 43:551-558.

24. Boekeloo BO, Schiavo L, Rabin DL, Conlon RT, Jordan CS, Mundt DJ. Self-reports of HIV risk factors by patients at a sexually transmitted disease clinic: Audio vs. written questionnaires. Am J Public Health 1994; 84:754-759. 